\title{
Memorias familiares. Un acercamiento desde el discurso de estudiantes universitarios
}

Family memories. An approach from the discourse of university students

\section{Dra. Juana Lorena Campos} vani@u.uchile.cl Facultad de Filosofía y Humanidades

Universidad de Chile

\section{Resumen}

El artículo exhibe relatos de memorias familiares realizados por estudiantes universitarios. No existe una pretensión de análisis de estos relatos, sino más bien la contemplación de cuán profundamente puede llegar un joven chileno, que no pertenece a una tradición del recuerdo ni del relato, a indagar a través de la palabra los andares de sus antepasados.

Cabe señalar, que estos estudiantes tuvieron como única motivación teórica, el conocimiento de la experiencia de memoria del pueblo judío.

Palabras clave: Historia Familiar - Genealogía - Biografía - Autobiografía

\begin{abstract}
The article showcases stories of family memories made by college students. There is no pretense of analyzing these stories, but rather contemplating how deep can get a young Chilean who does not belong to a tradition of memory and narrative, to inquire through the gait word of their ancestors.
\end{abstract}

It is noteworthy that these students had only the theoretical motivation, knowledge, experience memory of the Jewish people. 
Keywords: Family History - Genealogy - Biography - Autobiography

\section{Introducción}

La experiencia de recordar, si bien es propia de la judeidad, no lo es en la cultura urbana de Santiago de Chile. Ni respecto a la historia del país ni a la historia familiar. Como académica de la Universidad de Chile ${ }^{1}$ desde hace varios años estoy exponiendo a mis alumnos -en general no judíos- al encuentro con su propia historia familiar. Esto se inició como una forma de comprender qué es la memoria en el judaísmo, pero a poco andar se ha transformado en un fin en sí mismo, puesto que al igual que en el pueblo hebreo, la memoria genera identidad, pertenencia, consciencia de sí, y esto todos lo necesitamos.

Inicialmente los estudiantes se sienten curiosos, y al mismo tiempo temeroso sobre qué encontrarán en sus familias. Sin embargo se embarcan en una travesía impetuosa con increíbles ansias de conocimiento, cariño y honestidad.

Lo primero que llama la atención es la perplejidad de los estudiantes ante sus propias interrogantes: ¿por qué nunca antes me interesó mi historia familiar?, ¿por qué en mi familia no se habla de los antepasados?, ¿por qué tal o cual pariente no se nombra?

Y bien, se inicia un largo recorrido en que jóvenes de todo tipo de programas universitarios, frente al espejo de la memoria judía, comienzan a conocer quiénes son sus ascendentes. Junto a este proceso de recolección de datos, deben relatar sus hallazgos y es aquí donde nuestros jóvenes se revelan como narradores vívidos, extremos y francos, sin intención de rescatar figuras gloriosas, sino más bien de conocerlas profundamente, aun cuando esas

\footnotetext{
${ }^{1}$ Durante estos últimos cinco años he dictado los siguientes programas que son cursados por estudiantes en general no judíos: Memorias familiares y escrituras. La experiencia judía en la escritura íntima (2014); Multiculturalidad en el judaísmo: aproximaciones desde el cine y la literatura (2011-2014); El cine como representación de la memoria judía (2013); Judaísmo: experiencias multiculturales contemporáneas (2010)
} 
figuras sean los seres que nuestros abuelos escondieron en cuartos oscuros por vergüenza, miedo o maldad.

A diferencia de los narradores judíos, los jóvenes universitarios no escriben para rescatar un pasado y un pueblo, escriben fundamentalmente para conocerse a sí mismos, para conocer su historia, en fin, intentar conocer su origen y destino. Estos jóvenes no pertenecen a una tradición del recuerdo ni a una tradición del relato y escucha, recién comienzan a caminar por los beneficios de las palabras familiares y los ecos perdidos. Entonces, la riqueza de conocer y relatar la historia familiar es un verdadero detonante para su propia identidad y aceptación.

\section{Algunas aclaraciones teóricas}

Los estudios de la memoria son cada vez más atendidos por las disciplinas que tratan lo humano. El judaísmo, mucho antes de estudiar la memoria, la vivía (Yerushalmi, 1984, 2002). Pareciera que la cultura latinoamericana y, especialmente la chilena, ha debido hacer el proceso inverso: estudiarla para poder vivirla. Revisemos, entonces, lo que plantean algunos teóricos.

Elizabeth Jelin (2002) dice que la memoria es del individuo y de la sociedad:

Las memorias son simultáneamente individuales y sociales, ya que en la medida en que las palabras y la comunidad de discurso son colectivas, la experiencia también lo es. Las vivencias individuales no se transforman en experiencia con sentido sin la presencia de discursos culturales, y éstos son siempre colectivos. A su vez, la experiencia y la memoria individuales no existen en sí, sino que se manifiestan y se tornan colectivas en el acto de compartir. O sea, la experiencia individual construye comunidad en el acto narrativo compartido, en el narrar y el escuchar. (p. 37) 
Para Maurice Halbwachs (2004), el padre de los estudios de memoria colectiva, el marco de la memoria familiar es el sostén del relato y sólo gracias a este marco social es posible que la memoria surja y se construya como un pasado significativo. El autor también plantea que la idea de domicilio fija al individuo a la familia, ésta al hogar y el hogar al suelo. Aquí se produce un sentimiento de pertenencia, el mismo sentimiento que narradores buscan al escribir sus genealogías.

Plantea Halbwachs: "Si se busca un marco de nociones que nos sirva para evocar los recuerdos de la vida doméstica, se piensa de inmediato en las relaciones de parentesco, tal como han sido definidas en cada sociedad" (2004, p.193). De esta manera, el marco social que provee la familia a los autobiógrafos, les permite recordar y ejercer el rol transmisor de la memoria.

Silvia Molloy (1996) también atribuye a la familia un rol fundamental en el rescate de la memoria:

Que la memoria de Sarmiento, como individuo, haya adoptado la forma de reflexión genealógica -una convocación de precursores con quienes se identifica- no es casual. Desde el Inca Gracilazo, que de niño escuchaba absorto a su madre y a sus tíos evocar un compartido pasado incaico a punto de extinguirse, hasta Borges, que en la dedicatoria de sus Obras completas agradece a su madre "tu memoria y en ella la memoria de los mayores", el pasado en Hispanoamérica se ve como un asunto de familia. (p. 212).

Para Molloy, la familia es el soporte fundamental del recuerdo del pasado, ya que según los autobiógrafos no rescatar el pasado y su memoria es sufrir una pérdida: 
La ampliación y el enriquecimiento de la memoria van acompañados en casi todas las autobiografías por el temor, no menos general, a experimentar pérdida. El autobiógrafo hispanoamericano se caracteriza por su fuerte vocación testimonial: no se considera meramente testigo de ese pasado amplificado, es el único testigo de una época concluida que sólo vive en su relato (...) el pasado, hasta el pasado propio, es un anacronismo, condenado a morir si no se lo rescata dando testimonio de él. (1996, p. 216)

Jelin, también comparte la pertenencia al grupo como soporte para la memoria, dice en el texto citado anteriormente:

La memoria tiene entonces un papel altamente significativo, como mecanismo cultural para fortalecer el sentido de pertenencia a grupos o comunidades. A menudo, especialmente en el caso de grupos oprimidos, silenciados y discriminados, la referencia a un pasado común permite construir sentimientos de autovaloración y mayor confianza en uno/a mismo/a y en el grupo (2002, p. 10)

Entonces, la memoria junto con revitalizarse en marcos sociales, como lo plantea Halbwachs, le da al individuo una pertenencia de grupo, afianzándolo en un domicilio social. Por esta razón, el rescate de la memoria que realizan nuestros jóvenes narradores es más que una mera exhibición de su genealogía, es tomar un lugar en el mundo, ubicarse, establecerse, construir una residencia. Jelin, conociendo los postulados de Halbwachs, confirma la importancia de las redes sociales en la mantención de la memoria, fija parámetros de identificación grupal con unos y de separación con otros, así se definirían los límites de la identidad. Esta idea de límites identitarios funcionarían como marcos sociales que encuadran la memoria. 


\section{Memorias Familiares}

Los textos que a continuación se presentan -con la aprobación de sus autores- han sido seleccionados por ser bellísimos relatos por donde corre la nostalgia, la aceptación del propio pasado, la curiosidad y el asombro de una historia que, por momentos, se revela fresca y diáfana.

Estos autores han dedicado a sus relatos familiares mucho tiempo. Lo que aquí se expone es solo un retazo de su trabajo, sin embargo muestra la inspiración que puede lograr el conocimiento de una cultura que sienta sus bases en la memoria como lo es el judaísmo.

\section{TEXTO 1. Sofía Miranda Valdebenito}

Había escuchado varias veces que mi tatarabuelo paterno se cambió el apellido a la mala. Según dice mi abuelita, fue porque se avergonzó de su hermano que se arrancó con su amante y dejó a su esposa e hijos. A Polito, le impactó tanto el hecho que en vez de darles a sus hijos su apellido: Villalobos, los bautizó como Lobos para así desligarse de la familia.

Y es el desligarse lo que se transformará en la marca de mis antepasados. Elemento presente tanto en muertes repentinas, accidentadas y hasta violentas, como en sus inútiles esfuerzos por mejorar la suerte. En mi familia materna solo existen recuerdos de la mamita Aurora, mi bisabuela, una mujer de carácter fuerte, dueña de casa y campesina viuda, que según la mayor de mis tías-abuelas le daba cacerolazos en la cabeza y correazos por ser la más morena de sus hijas. Mi tatarabuela tuvo solo una hija que acarreó por diversos pueblos del sur, ya que trabajaba como guitarrista en toda fonda, 
funeral, matrimonio, etc. que se presentara. Y por último está la finada Berta, una mujer que murió joven y que siempre que se nombraba se hablaba de su obsesión por limpiarse los pies, hasta el punto de pagarle a cualquier persona para ir a trabajar por ella, solo por el placer de quedarse en su pieza observando cada uno de sus dedos. Recientemente descubrí que la finada era hermana de mi abuela, algo que nunca hubiese pasado por mi cabeza, dada la forma en que se la llamaba.

El campo ha sido el escenario de todo lo materno, con mujeres que rociaban hijos sin padres y con un destierro hacia Santiago que nunca se ha superado. La cadencia de hombres fantasmas se hibrida en elecciones de maridos que siempre están ausentes y de los que se debe mantener el recuerdo. Una reafirmación obligada de su presencia.

Por el lado de mis ancestros paternos, solo esbozaré las figuras de mi bisabuelo, mi abuelo y mi padre. Mi bisabuelo, fue escritor y director de teatro, empeñó todo su dinero para montar obras escritas por él, nunca recuperó sus inversiones y se vio obligado a usar su auto como taxi para mantener a sus hijos. Su esposa, mi bisabuela, se separó de él y lo dejó con los niños. Fue asesinado al poco tiempo por una mujer con la que estaba saliendo. Los niños fueron llevados con su madre y ella a su vez los internó en escuelas para trabajar tranquila. Mi abuelo se recibió de diseñador gráfico, hizo el servicio militar y luego se fue a vivir con su madre. No pretendía casarse, pero tras siete años de pololeo lo hizo a la edad de 35 años. Tuvieron dos hijos, compraron un departamento y también una sepultura familiar. Mi padre no quiso estudiar y consiguió un trabajo administrativo en el JJ Aguirre, donde conoció a mi madre, ella se embarazó y se casaron. Tuvieron dos 
hijas. Cuando mi hermana menor había cumplido un año quisieron ir a la playa por un fin de semana. Ese viernes mi padre salió de la oficina y fue al bar del frente. En ese tiempo se hacían redadas a cualquier hora, en cualquier lugar y a cualquier persona. Una de ellas fue al bar que estaba frente al hospital, carabineros sacó a todos los que estaban dentro, los hicieron salir en fila y a uno de ellos le dispararon en la cabeza. Lo llevaron con el cráneo abierto al mismo hospital donde trabajaba y dijeron que era un extremista que estaba haciendo disturbios. A pesar de la desfiguración los médicos reconocieron a mi padre. Estuvo cuatro días en estado vegetal y fue desconectado el 29 de junio de 1987. El carabinero que disparó fue dado por muerto y el Juzgado Militar sobreseyó el caso.

TEXTO 2. Javiera Isidora Fernández Ropert

\section{Un hombre del siglo XX}

A la memoria de mi abuelo, gracias a él estudio Historia.

Enrique Ropert nació en Valparaíso un año y medio antes de que explotara la Gran Guerra. Ojos verde agua, carácter bretón y dueño de las manos de pianista más hermosas que jamás haya visto, nadie sabe con certeza cuándo empezaron a llamarle el viejo Ropert. Irreverente e iracundo, era común escucharlo gritar “ipor la [re]chupalla del gobierno!” y, si era una situación realmente grave, “ipor la carabina del paco Ibáñez!”. 
La casa de su infancia es hoy sede de una Universidad o un Instituto Técnico, ya no lo recuerdo - la memoria puede ser preocupantemente frágil. Solo sé que esa casa sigue en pie y que fue una de las pocas propiedades que su familia no perdió tras la Gran Depresión del '29. Y, si creemos en las leyendas familiares, se dice que la ruina fue tal que hasta tuvieron que vender un castillo emplazado en alguna nación europea.

Ingeniero, físico y agrónomo, tenía un taller de estructuras metálicas junto con su hermano mayor. Luis, el ingeniero Ropert, no se había titulado pero era reconocido en el mundo de la ingeniería. Alguna vez alguien me contó que él había propuesto en la década del '60 hacer un metro en Santiago y que le habían respondido que era una locura construir una red de transporte subterránea en un país sísmico. Por esas locuras mi abuelo lo recordaba como el hombre más brillante que jamás había conocido. Probablemente esto no lo deba contar, pero para solucionar el dilema entre el prestigio del hermano y su falta de título, Enrique cambió su firma a Luis Ropert y así poder estampar su nombre en los planos. Esa era una de sus tantas locuras.

Antes de casarse con mi abuela, estuvo comprometido con la Pichona. El noviazgo se rompió una semana antes del matrimonio -con los partes enviados y los regalos en la casa- por una pelea sobre política en plena Segunda Guerra Mundial: su suegro era alemán y Enrique francés. No había cómo conciliar posiciones ni nada que hacer al respecto. 
Terminó casándose con Miria Contreras, la Payita, hija de un abogado radical - “cuando ser radical era ser revolucionario"- como siempre recalca mi madre. Con ella tuvo tres hijos: Isabel, la luz de sus ojos, Enrique y Max. En 1961 fue aceptado en una Universidad parisina para estudiar Física Nuclear, así que arrendaron su casa en Providencia, hicieron maletas y se fueron tres años a Francia. Allá compró una casa rodante en la cual recorrieron Europa durante las vacaciones. No habían pasado veinte años del fin del régimen nazi, cuando él los llevó a conocer las ruinas de los campos de concentración. Isabel nunca pudo olvidar el horror del escenario y aquello terminó influyendo profundamente en la posición política que abrazaría -al igual que sus dos hermanos- casi una década después.

De regreso a Chile, Enrique compró un fundo en Camarico llamado San Jorge. Quiso cambiarle el nombre a Château Ropert, pero tuvo que echar pie atrás porque los campesinos empezaron a decirle el Chato Ropert. Allí se dedicó a la agronomía. Haciendo gala de su sentido del humor único, fundó la Viña Conchetuma y produjo un vino que él clasificó como tipo achuchamadreado. Sus hijos y sobrinos pasaron veranos completos en el fundo cabalgando todos juntos en el mismo caballo percherón, haciendo guerras de sandías y fumando hojas de árboles cuando se quedaban sin cigarrillos. Eran tiempos de Frei Montalva y las grandes propiedades agrícolas. Enrique, socialista como pocos van quedando, diseñó y mandó a construir el sistema de agua potable y luz eléctrica para las viviendas de los trabajadores del fundo. Pero habría que esperar hasta el gobierno de la Unidad Popular para que se le aplicase -por petición explícita de él- la Reforma Agraria. 
Uno de los sueños de Enrique era formar la Compañía Constructora del Estado y éste se materializó cuando entró a trabajar en el MOP durante el gobierno de Allende. Consecuente con sus principios éticos, cerró el taller de estructuras metálicas porque consideraba que un hombre que se dedica al mundo público no puede ejercer paralelamente en la esfera privada. El lunes siguiente al golpe de Estado de 1973, él se presentó a trabajar. Le faltaban meses para cumplir los 61 años. Allí fue detenido, esposado y llevado al Estadio Nacional. Sabía que su hijo Enrique había sido detenido cuando llevó a su madre a La Moneda el 11 de septiembre en la mañana. Intuía que su ex mujer había resistido al bombardeo de La Moneda, pero no tenía certezas si había logrado escapar después de la rendición. Había logrado reunirse con el menor, Max. Pudo contactarse con Isabel y supo que su nieto José Miguel de 9 meses estaba escondido. Pero no habían noticias sobre el paradero de su hijo Enrique.

Uno de esos días - uno de esos largos días - un clérigo visitó a los presos políticos del Estadio. Enrique solo exclamó “traigan putas, no curas”. ¿Será el sentido del humor un elemento fundamental para la supervivencia en esas condiciones? Trasladado a la Cárcel Pública, su abogado hizo las gestiones para que el gobierno francés lo reclamara y él pudiese partir al exilio. Su técnica fue infalible: se hizo pasar por loco.

Vivió el exilio entre Francia y Cuba. Cuando encontró trabajo en el primer país, no ganaba lo suficiente y debía caminar todos los días una hora para llegar a su trabajo, otra para volver a su casa. Así se mantuvo hasta que se unió al sindicato de la empresa, llamó a huelga y lo jubilaron. Al poco tiempo descubrió que los ciegos no pagaban la entrada 
para los museos, así que sacaba a pasear a su nieto usando anteojos oscuros y bastón. José Miguel le seguía el juego mientras lo llevaba del brazo y le iba describiendo las obras que tenía al frente. El nivel de complicidad entre ambos no tenía límites.

Viajó clandestino a Chile en la década del '80. Tenía setenta años. Uno de sus planes para recuperar la democracia era armar la resistencia desde Isla de Pascua, plan que, por supuesto, jamás alguien tomó en serio. Retornó definitivamente a Chile durante el primer gobierno de la Concertación. Tras algunos años viviendo en Santiago, se instaló en Santo Domingo y, cada vez que tenía la oportunidad, nos recordaba que junto a su hermano habían diseñado la urbanización de dicho balneario. Durante los meses de verano él se lanzaba de piquero a la piscina de su casa y nadaba algunos largos. No sería memorable si no fuera por el hecho de que lo hizo hasta sus 97 años.

Planeaba todos los años su fiesta de cumpleaños en diciembre y estaba empecinado a celebrar sus 100 años con toda su familia. Se fue el 1ro de enero después de haber deseado feliz año nuevo. Era su 101 Año Nuevo y se acababan las locuras de un siglo.

\section{TEXTO 3. Abigail Esperanza Ureta Fredes}

Familia. Un concepto arraigado, con una importancia vital para las sociedades y la conformación de la vida, pero ¿Qué tan importante llega ser para nosotros? 
Muchas veces queremos creer que estamos formados por las cosas que nos trae la vida, por nuestras experiencias y la realidad, pero la carga de nuestros ancestros está con nosotros, la arrastramos y convivimos con ella, nos determina y nos lleva a crear una nueva identidad, formada por la herencia.

¿Cómo cambian las circunstancias a lo largo del tiempo? Mi familia materna, mi tatarabuelo, Juan Rossello Carbonelli, el inmigrante, aquel italiano que llega a Chile escapando de la guerra, confiando en un mundo mejor, un comerciante de telas que trae consigo la fortuna familiar y la herencia de la madre patria. Al llegar a Chile se instala en Santiago y conoce a Rosenda, una mujer que le cambia la vida, sus cinco hijos, tienen la misión de mezclar la cultura y formar la familia Rossello-Gómez.

Zoila Esperanza, la primera de las muchas Esperanzas que vendrán, era una mujer que siguió la tradición comercial de la familia, aumentando las arcas de la fortuna familiar, un día y deslumbrada por la voz de un bohemio cantor de tango, queda prendada de Rubén Guerra, mi bisabuelo. Su padre, Guillermo Guerra Valdivieso, dueño de minas de plata en el norte del país, se dio a la locura, su dinero se lo llevo el viento. Se dice que lo ocupaba como papel higiénico, que lo tiraba por las ventanas y se lo comía, abandonó a su suerte a su mujer y a sus cinco hijos, de aquí que mi bisabuelo Rubén elige la vida bohemia, para ahogar las penurias de su infancia. En los años que vendrán, sus hermanos, dados a la locura familiar, pierden su vida en busca de la fortuna perdida del abuelo Valdivieso. 
Mi bisabuela Esperanza Rossello, con cuatro hijos y un esposo guiado por la noche y sus placeres, es expulsada del círculo familiar por el matrimonio mal habido y su patrimonio gastado en manos de las fiestas y los vicios de su esposo, condenada a trabajos extremos, muere de tuberculosis, acabando con el sueño inmigrante de sus padres. La primera de las mujeres condenadas como decía mi abuela, aquella que tuvo que empoderarse y tomar el lugar a la cabeza de la familia. Nos heredó, sin quererlo, la tradición del esfuerzo y el trabajo duro, el matriarcado obligado y las tristezas del porvenir.

Mi abuela, la segunda Esperanza, Esperanza Guerra, huérfana de madre a temprana edad y con un padre entregado a la vida, va de hogar en hogar, hasta que la vida, a la corta edad de 17 años se convierte en madre. Por las condiciones morales de la época y para no traer vergüenza a la familia, es obligada a casarse con el primer hombre que la acepta embarazada de otro hombre, mi abuelo Luis Fredes, 18 años mayor que ella. Huérfano de padre a temprana edad, nunca conoció a su madre; el mito dice que su padre se robó a una indígena mapuche de su comunidad y la trajo a Santiago a casarse. Mis abuelos, con cuatro hijos, viven del esfuerzo de mi abuela Esperanza, mi abuelo, un alcohólico empedernido, nos hace recordar cómo los errores familiares se repiten, cómo la herencia que arrastramos es fuerte y cómo aunque queramos, no se puede huir de nuestra familia. Tras la partida de mi abuelo, mi abuela y sus hijos se enfrentan a duras realidades, viviendo de allegados en donde se pudiera, mi abuela sola frente a la vida y con los años setentas en el apogeo de su violencia, recurre a su tradición comercial, trabajando en quioscos, en la feria o donde se pudiera. Mi madre, la tercera Esperanza, toma el poder frente a sus hermanos, frente a la ausencia de mi abuela en las horas de trabajo, ayuda a 
mi abuela a sacar adelante a la familia. Dos hijos esquizofrénicos y uno con síndrome Asperger, era suficiente para cargar. Conseguir una casa, darle estudios a sus hijos, trajo un próspero porvenir, un tiempo en que se pensaba que todo sería diferente.

Esperanza Fredes, mi madre, tras su dura infancia, y en una fiesta de su comunidad, es deslumbrada por la personalidad y alegría de Guillermo Ureta, mi padre. Embarazada de mi hermano mayor, es obligada a casarse, con un hombre aficionado a la vida y a sus vicios, que ha dejado en las drogas la mitad de su vida y la mitad de la mía. Sus padres, Carmen Marín y Leonidas Ureta, se casan en segundas nupcias tras enviudar, cada cual con hijos de su matrimonio anterior, entre ellos tienen siete, conformando una familia de 14 personas, supongo, que este abandono entre tantos hijos, generó al eterno adolescente despreocupado que es mi padre. De esta familia no se mucho, no me interesa saber, no buscaré explicaciones en su familia de su razón de ser ni por qué tuvo que tocarme a mí, solo sé que es mi padre, el que me dio la vida, pero no el que la ha vivido conmigo.

Enfrentada a esta realidad, mi madre, junto a uno de sus hermanos, toma a la vida por las riendas y no permite que su realidad la aplaste. Hizo lo posible para mantener a su familia, nos sacó del campamento, nos puso en la universidad y nos abrió las puertas hacia una vida inesperada por las generaciones pasadas, en donde el futuro está abierto y cercano, dispuesto a recompensar los sufrimientos de la vida pasada.

Yo, Abigail Esperanza, la cuarta Esperanza, me enfrento a esta realidad, la mochila que cargo diariamente ¿Repetiré los errores del pasado? ¿Seré capaz de crear una nueva 
realidad? No me llamé Esperanza porque, cuando aún estaba en el vientre de mi madre, mi abuela le dijo que si me colocaba ese nombre no le hablaría más, era un nombre maldito y todas las Esperanzas tenían mala suerte. Me encantaría creer que él no cargar con el nombre familiar, me librara de los sufrimientos de la vida, que a mis 23 años he conocido muchos más de lo que me gustaría, pero las cosas pasan y la enseñanza que me ha sido dada por la historia, es lo que me salvará de la tradición.

Las mujeres de mi familia, las Esperanzas, esas que con ahínco y valor han tenido que enfrentar la vida, luchando contra las asperezas del camino y con los hombres que les han traído mal, que por sus hijos han dado esta vida y la siguiente. Estas mujeres son mi pasado, mi presente y mi futuro, la herencia de la que me enorgullezco, la que me hace botar lágrimas cuando escribo, las que me han moldeado de cero, su ejemplo y su labor, han creado mi persona, mi identidad, mi familia.

\section{Texto 4. Pablo Andrés Mena Meléndez}

Recuerdo haber oído bastante de mi abuelo, la mayoría de estas historias me han parecido iguales en esencia, siempre contando cómo solía meterse en peleas, ya sea borracho o no, cuando llevaba a mi padre a cazar con sus tíos a caballo y la relación poco afectiva que tuvieron entre sí. Todo me hacia pensar en que tales historias giraban en torno a la actitud firme y ahombrada de mi abuelo, que si bien nunca me causaron ni repelencia ni admiración, me parecía imaginar simplemente el carácter casi folclórico de un hombre de campo. Él era carnicero (aspecto que hace resaltar aún mas su 
personalidad, creo yo), mi padre me contó cómo mataba chanchos con un machete sobre una mesa grande de palo, mesa sobre la cual, años más tarde, mi hermano y yo jugábamos a hacer espaditas.

Un día mi padre se clavó una espina en el pie, mi abuelo le afirmó la pierna del mismo modo en que le sujetaba las patas a los caballos para clavarles las herraduras, tomó una gillette y le abrió un tajo para poder sacar la espina, la sangre saltó por la infección (tal vez una exageración de mi padre al contarme esto), la espina llevaba varios días en su pie, y mi padre no había querido decirle nada a mi abuelo por temor a que esto pasara, pasó de todos modos.

Mi abuelo murió al caerse de un camión alrededor de la década de los sesenta, no lo conocí, ni sabría decir si me hubiese gustado o no, no por miedo, ya que al parecer era muy cariñoso con sus nietos, sino por el hecho de suponer que la imagen que tengo de él no sea la de las historias, si bien para mi es un "fantasma" hecho a base de cuentos, me he encariñado con él.

No he escuchado nada sobre su funeral ni sobre lo triste que fue el duelo, como me suelen contar sobre otros miembros de mi familia. 


\section{A modo de conclusión}

Los grandes secretos de las culturas milenarias, pareciera que no están exclusivamente en sus sabios y pensadores. Pareciera que las culturas que cruzan milenios a través del tiempo se apoyan en cotidianeidades que hasta el individuo más simple y sencillo de la comunidad puede cumplir. A mi parecer, en el judaísmo, contar la memoria familiar de generación en generación es aquella cotidianeidad fundamental.

Los estudiantes que han conocido la memoria judaica se inclinan a indagar su propia historia íntima, la de su familia. Esto los territorializa, les da identidad y fortaleza. En estos aspectos no hay diferencias penosas entre los judíos y los no judíos.

\section{Bibliografía}

Begué, M. F. (2006). El estatuto epistemológico del testimonio. Una manifestación diferente de la verdad. En P. Mena (Comp.) Fenomenología por decir. Homenaje a Paul Ricoeur. Santiago, Chile: Universidad Alberto Hurtado.

Bursztein, A. (1999) La alienación como punto de partida de la Identidad. Recuperado el 25 de junio de 2008 del sitio web Hagshama:

http://www.hagshama.org.il/es/recursos/view.asp?id=486

Catelli, N. (2007). En la era de la intimidad: Seguido de, El espacio autobiográfico. Rosario. Argentina: Beatriz Viterbo.

De Man, P. (1991). La autobiografía como desfiguración. Anthropos: Boletín de información y documentación, 29, 113-118. 
Foucault, M. (1999). ¿Qué es un autor? En Obras esenciales. Vol.1 Entre filosofía y literatura. Barcelona. España: Paidós.

Foucault, M. (2004). La arqueología del saber. Buenos Aires. Argentina: Siglo XXI.

Halbwachs, M. (2004). Los marcos sociales de la memoria. Barcelona. España: Anthropos; Concepción. Chile: Universidad de Concepción; Caracas. Venezuela: Universidad Central de Venezuela.

Hirsch, M. (1997). Family frames: photography, narrative and postmemory. Cambridge. EE.UU: Harvard University Press.

Huberman, A. \& Meter, A. (Comps.) (2006). Memoria y representación. Configuraciones culturales y literarias en el imaginario judío latinoamericano. Rosario. Argentina: Beatriz Viterbo.

Jelin, E. (2002). Los trabajos de la memoria. Madrid. España: Siglo XXI.

Lejeune, P. (1994). El pacto autobiográfico y otros estudios . Madrid. España: MegazulEndymion.

Massmann, S. (2005). Árbol genealógico y álbum de familia: dos figuras de la memoria en relatos de inmigrantes judíos. Estudios Filológicos, 40, 131-137.

Molloy, S. (1996). Acto de presencia. La escritura autobiográfica en Hispanoamérica. México D.F.: Fondo de Cultura Económica.

Morales, L. (1999). Género y discurso : el problema del testimonio. Mapocho. No. 46. 167176. 
Morales, L. (2001). La escritura de al lado : géneros referenciales. Santiago. Chile: Cuarto Propio.

Morin, E. (1994). La noción de sujeto. En Fried, D. (Comp). Nuevos paradigmas, cultura y subjetividad (67-89). Buenos Aires. Argentina: Paidós.

Yerushalmi, Y. H. (2002). Zajor: la historia judía y la memoria judía. Barcelona, España: Anthropos; México: Fundación Cultural Eduardo Cohen.

Yerushalmi, Y. H. (1984). Reflexiones sobre el olvido. Buenos Aires. Argentina: Nueva Visión. 